\title{
Esportes eletrônicos na pauta da mídia sonora: levantamento de podcasts na plataforma de streaming Spotify ${ }^{1}$
}

\author{
Electronic sports on the agenda of sound media: \\ survey of podcasts on the Spotify streaming platform
}

\section{Los deportes electrónicos en la agenda de los medios sonoros: encuesta de podcasts en la plataforma de transmisión de Spotify}

\author{
Ariane Barbosa Lemos \\ Universidade do Estado de Minas Gerais - MG - Brasil \\ Endereço Currículo Plataforma Lattes: http://lattes.cnpq.br/9980543065359206 \\ ORCID: https://orcid.org/0000-0002-2050-3655 \\ E-mail: prof.arianelemos@gmail.com \\ Ayllana da Cunha Ferreira \\ Universidade do Estado de Minas Gerais - MG - Brasil \\ Endereço Currículo Plataforma Lattes: http://lattes.cnpq.br/1268296667117703 \\ ORCID: https://orcid.org/0000-0002-4958-1251 \\ E-mail: ayllanaferreira@gmail.com
}

Resumo: Este trabalho apresenta um levantamento dos podcasts sobre esportes eletrônicos disponibilizados na plataforma de streaming Spotify. A pesquisa qualitativa, de caráter exploratório e descritivo, investiga a relação entre informação e entretenimento no contexto da cobertura dos esportes eletrônicos da mídia sonora. Os 35 programas identificados foram analisados considerando aspectos relacionados à "editoria" e ao "enfoque". Os pontos discutidos revelam que o infotenimento predomina diante da ausência de profissionalização da cobertura midiática dos esportes eletrônicos. Os achados apontam, ainda, a hibridização na especialização da cobertura midiática, mesclando recortes do jornalismo cultural e do esportivo.

Palavras-chave: Mídia sonora. Esportes eletrônicos. Infotenimento. Podcast.

Abstract: This research presents a survey of podcasts on electronic sports made available on the Spotify streaming platform. Qualitative research, exploratory and descriptive,

\footnotetext{
${ }^{1}$ Este artigo apresenta um recorte dos resultados de pesquisa de TCC defendido e aprovado em março de 2021. Dados parciais foram publicados no $43^{\circ}$ Congresso Brasileiro de Ciências da Comunicação, realizado na modalidade virtual em dezembro de 2020.
} 


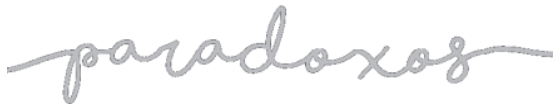

Esportes eletrônicos na pauta

da mídia sonora:

levantamento de podcasts na

plataforma de streaming Spotify

LEMOS, FERREIRA, 2021

investigates the relationship between information and entertainment in the context of the coverage of electronic sports in the sound media. The 35 identified programs were analyzed considering aspects related to "editorial" and "focus". The points discussed reveal that infotainment predominates in the absence of professionalization of media coverage of electronic sports. It also points out the hybridization in the specialization of media coverage, mixing clippings from cultural and sports journalism.

Keywords: Sound media. Esports. Infotainment. Podcast.

Resumen: Este documento presenta una encuesta de podcasts sobre deportes electrónicos disponibles en la plataforma de transmisión Spotify. La investigación cualitativa, exploratoria y descriptiva investiga la relación entre información y entretenimiento en el contexto de la cobertura de deportes electrónicos en medios sonoros. Los 35 programas identificados fueron analizados considerando aspectos relacionados con "editorial" y "enfoque". Los puntos discutidos revelan que el infoentretenimiento predomina en ausencia de profesionalización de la cobertura mediática de los deportes electrónicos. También destaca la hibridación en la especialización de la cobertura mediática, mezclando recortes de periodismo cultural y deportivo.

Palabras-clave: Medios de sonido. Deportes electrónicos. Infoentretenimiento. Pódcast.

\section{Introdução}

Com a popularização dos jogos de fliperama e o início das primeiras competições online, a partir dos anos 2000, os jogos eletrônicos tornaram-se uma fonte de renda e uma modalidade de profissão. Como resultado, surgiu a figura dos cyber atletas, jogadores profissionais de esportes eletrônicos. Antes, a modalidade era associada aos games e, por isso, considerada apenas ao lazer e ao entretenimento passou a ser vista como um setor de investimento que reúne plataformas de apostas em competições acaloradas capazes de mobilizar grandes torcidas e movimentar as redes sociais.

Este artigo dedica-se a estudar a categoria dos esportes eletrônicos tendo como recorte o contexto brasileiro. A intenção é caracterizar a cobertura midiática, especialmente aquela protagonizada pelos podcasts, um formato de mídia sonora em franca popularização. Assim, a reflexão proposta orienta-se pela seguinte indagação: considerando os podcasts disponíveis na plataforma de streaming Spotify, quais são as características da cobertura midiática dos esportes eletrônicos? 


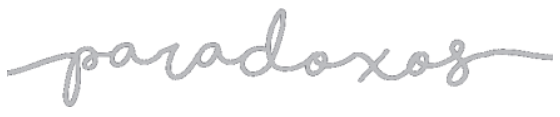

Esportes eletrônicos na pauta

da mídia sonora:

levantamento de podcasts na

plataforma de streaming Spotify

LEMOS, FERREIRA, 2021

A partir dessa problematização tem-se uma pesquisa cujo objetivo é analisar os aspectos do infotenimento na cobertura midiática do segmento, considerando o contexto brasileiro de produção de podcasts. Para isso, contou-se com um levantamento dos podcasts disponíveis na plataforma de streaming Spotify que a abordam a temática esportes eletrônicos. No mapeamento, tem-se um diagnóstico da cobertura midiática dedicada à modalidade, observando a relação entre informação e entretenimento e sistematizando as características da cobertura dos esportes eletrônicos.

Neste contexto, os eSports esportes eletrônicos têm um mercado consumidor próprio, indicando alto potencial econômico, devido à sua movimentação financeira com patrocínios, contratos publicitários e apostas, e midiática, tendo em vista da cobertura de temas correlacionados e da mobilização de público interessado na temática. Em outras palavras, "o grande sucesso que o cenário vem fazendo e a grande quantidade de dinheiro envolvida fizeram com que a mídia enxergasse o eSport como uma oportunidade." (LIMA; MOTA, 2019, p. 03).

\section{Esportes eletrônicos: características, origens e interesse midiático}

Um dos principais pesquisadores da história cultural, Johan Huizinga (18421975), analisa o jogo como elemento da cultura na obra Homo Ludens. O historiador aponta que os jogos são uma das formas pela qual a sociedade exprime sua interpretação da vida e do mundo. Portanto, eles são um elemento social, alimentado por várias particularidades do coletivo (HUIZINGA, 1980). Os diversos tipos de jogos convergiram para outras plataformas, um exemplo disso são os jogos de tabuleiro que no contexto digital inauguraram a categoria dos esportes eletrônicos.

No Brasil, a modalidade competitiva dos jogos digitais é regido pela Confederação Brasileira de eSports (CBeS). A entidade define a categoria como sendo uma competição na qual atletas ou equipes participam de competições e disputam premiações. Campos e Frange (2017, p. 61) apontam que há uma "[...] relação direta com a profissionalização do jogo e funciona como um símbolo, uma recompensa pelo esforço e dedicação dos jogadores ganhadores”. Dessa forma, o eSport é carregado pelo universo simbólico e narrativo do esporte, com rituais, profissionalização e a corrupção do 


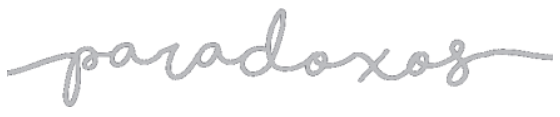

Esportes eletrônicos na pauta

da mídia sonora:

levantamento de podcasts na

plataforma de streaming Spotify

LEMOS, FERREIRA, 2021

universo lúdico. No entanto, também não é apenas esporte. É uma simbiose entre o esporte e o videogame, que cria uma terceira atividade, também com raízes lúdicas, mas que conta com uma série de peculiaridades. (BERNARDO, 2016, p. 43).

\section{Profissionalização}

Para Dallegrave (2018), os jogos de fliperama são o primeiro passo na história dos eSports. A estreia de competições oficiais de esportes eletrônicos aconteceu em 19 de outubro de 1972, na Universidade Stanford, nos Estados Unidos. Na ocasião, jovens universitários criaram as Olimpíadas Intergaláticas de Spacewar com duas modalidades de competição. (HAGUI, 2018).

Até o fim da década de 1990, as competições passaram a ser realizadas com certa periodicidade, ampliando o número de participantes e de visibilidade. A partir dos anos 2000, com o maior acesso à internet e a popularização dos jogos de console $^{2}$, os eSports conquistaram novos fãs e mais espaço no universo da cultura nerd. Como exemplo, segundo a Confederação Brasileira de eSports, tem-se a realização de dez campeonatos oficiais de eSports durante o ano 2000. Em 2010, foram 160. Em suma, a internet superou os limites físicos e geográficos, possibilitando novos tipos de competições, o surgimento de famosos torneios internacionais e a consolidação dos já existentes. Naquele mesmo ano, surgiram os primeiros times profissionais, compostos pelos cyber atletas. Um pouco após, em 2015, outro fato chama atenção. Aconteceu o primeiro evento com o tema principal "esportes eletrônicos". $\operatorname{Logo}$, a temática se tornou protagonista de eventos específicos e deixou estrelar entre as grandes atrações das feiras específicas.

Ao mesmo tempo que o público presencial crescia, acontecia um movimento paralelo no consumo online. Tanto é que, conforme aponta Reis (2018), estima-se que mais de 102 milhões de pessoas utilizaram a plataforma de streaming de jogos Twitch-tv, em 2018. A modalidade esportiva atingiu um novo patamar no qual as pessoas passaram a assistir e valorizar a transmissão das competições, antes mesmo de jogar. Como

\footnotetext{
${ }^{2}$ Nome dado a um aparelho eletrônico, semelhante a um microcomputador, dedicado a executar jogos eletrônicos.
}

DOI: http://doi.org/10.14393/par-v6n1-2021-60844 - Paradoxos, Uberlândia, v. 6, n. 1, p. 86-102, jan./jun. $2021 \mid 89$ 


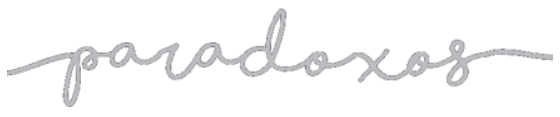

Esportes eletrônicos na pauta

da mídia sonora:

levantamento de podcasts na

plataforma de streaming Spotify

LEMOS, FERREIRA, 2021

exemplo, segundo Sport TV (2018), o Brasil tem cerca de 7,8 milhões de brasileiros que assistem a campeonatos, sendo a terceira maior audiência mundial.

\section{Cobertura da midiática}

Os eSports pautam a produção de produtos jornalísticos, integrando as agendas de dois tipos de cobertura dos veículos de comunicação: a cultural, devido ao vínculo de representatividade com determinado grupo social; e a esportiva, tendo em vista o interesse em cobrir as competições promovidas. Ou seja, à medida que o jornalismo de games, com ênfase em eSports, se enquadra em cultura, Campos e Frange (2012), Kurtz e Torrealba (2018) e Lima e Mota (2019) defendem a ideia de que o segmento é, primordialmente, parte do universo dos esportes tradicionais. Alinhando-se aos esportes, caberia aos eSports uma cobertura jornalística semelhante àquela feita dos eventos esportivos, a exemplo dos campeonatos de futebol.

Percebendo o potencial de audiência, grandes empresas de veículos de imprensa que cobrem os esportes tradicionais, como Sport TV e ESPN, criaram espaços em suas respectivas programações para a cobertura de pautas relacionadas aos esportes eletrônicos. As estratégias adotadas foram diversas: desde a criação de abas em seus portais de notícia e produção de podcast, até o desenvolvimento de vídeos para canal personalizado no YouTube, plataforma de compartilhamento de vídeos.

Em um movimento anterior, a mídia alternativa tem demonstrado bastante interesse pela cobertura dos esportes eletrônicos. Levantamento realizado por Ioscote (2018) revela que o YouTube permanece sendo o principal veículo no qual a audiência do segmento consome conteúdo e se sente informada. O Twitter também foi citado para acompanhar os atletas, equipes e jornalistas especializados.

O jornalismo é visto como um elemento essencial para a consolidação do universo dos esportes eletrônicos. Entende-se que o fazer jornalístico contribui para a formação de senso crítico na sociedade e para o "confronto" dos grandes conglomerados, normalmente, apoiadas pelos outros segmentos devido ao alto poder financeiro de boicote. lera

No que tange à relação entre esportes eletrônicos e podcasts, Freitas, Mendonça e Mustaro (2010) citam pesquisa feita pela PodPesquisa segunda a qual os games são o 


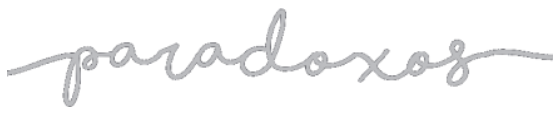

Esportes eletrônicos na pauta

da mídia sonora:

levantamento de podcasts na

plataforma de streaming Spotify

LEMOS, FERREIRA, 2021

quarto tema mais abordado, com 45,84\%. A estrutura dos podcasts, atrelado à maior valorização de conteúdos subculturais, como assuntos de tribos urbanas dos nerds, emos, crista, entre outros, cria-se um espaço para o crescimento e fortalecimento dos esportes eletrônicos dentro do estilo, como explicam os autores. Além disso, existe também a relação com o público-alvo, em que o consumidor de eSports prefere a internet para se informar por oferecerem um tipo de conteúdo mais livre.

Considerando, também, a relação com o jornalismo transmídia, os podcasts se tornam uma opção para a interatividade e o envolvimento necessários para atrair consumidores (usuários/ouvintes), auxiliando os esportes eletrônicos na sua conquista por maior espaço dentro da indústria de entretenimento.

\section{Levantamento: metodologia}

Para compreender as peculiaridades que constituem a cobertura feita pela mídia brasileira sobre os esportes eletrônicos, optou-se pela metodologia de levantamento. O principal método de coleta de dados é a análise de informações secundárias e a observação informal dos episódios dos podcasts. O levantamento foi realizado no Spotify na versão gratuita que permite acesso direto ao catálogo de áudios. A escolha por esta plataforma baseou-se na reportagem de Ferreira (2020) para a Rock Content que indica ser esta uma das mais acessadas pelo público brasileiro, tornando-se, portanto, uma referência para o estudo.

Entre os meses de setembro e novembro de 2020, foram realizadas buscas sistemáticas para identificar e mapear programas sobre esportes eletrônicos de forma parcial ou integral. Como primeiro passo, fez-se uma busca nas categorias disponíveis na plataforma, considerando as nomenclaturas: games, RPG e videogame. Na sequência, realizaram-se pesquisas aplicando palavras-chave relacionadas à cobertura e aos campeonatos de esportes eletrônicos.

$\mathrm{Na}$ filtragem dos programas identificados e de seus respectivos descritivos, foram analisados os podcasts que se autodeclararam específicos de esportes eletrônicos (integral) ou que se dedicam aos games e, eventualmente, produzem episódios abordando 
a temática eSports (parcial). Nesse último aspecto, consideraram-se, apenas, aqueles em que os jogos foram o tema principal de abordagem.

\section{Levantamento: apresentação e discussão dos dados}

O levantamento identificou e selecionou 35 programas conforme demonstrado no Quadro 1.

Quadro 1 - Podcasts sobre esportes eletrônicos no Spotify

\begin{tabular}{|c|c|c|c|c|c|c|}
\hline Programa & $\begin{array}{c}\text { Episódio } \\
\text { Analisado }\end{array}$ & Criação & Periodicidade & Equipe & $\begin{array}{c}\text { Veículo } \\
\text { associado }\end{array}$ & $\begin{array}{c}\text { Outros canais } \\
\text { de veiculação } \\
\text { (continua...) }\end{array}$ \\
\hline $\begin{array}{c}\text { Around the } \\
\text { Rift }\end{array}$ & \#165 & 2019 & Quinta-feira & $\begin{array}{c}\text { Eduardo Souza, } \\
\text { Alexandre } \\
\text { Trevisan, } \\
\text { Bernardo } \\
\text { Pereira, Kauê } \\
\text { Borges, Letícia } \\
\text { Motta, Diego } \\
\text { Oliveira e } \\
\text { Gustavo Cima }\end{array}$ & Mais Esports & $\begin{array}{c}\text { Site, Twitter, } \\
\text { YouTube, } \\
\text { Twitch }\end{array}$ \\
\hline $\begin{array}{c}\text { Café com o } \\
\text { Celtic }\end{array}$ & $\begin{array}{c}\text { Café com } \\
\text { celtic e coreia }\end{array}$ & 2018 & Não informada & Celtic & $\begin{array}{c}\text { Café com } \\
\text { Celitic }\end{array}$ & - \\
\hline $\begin{array}{l}\text { Central } \\
\text { Esports }\end{array}$ & $\# 180$ & 2017 & Não informada & Rodrigo Guerra & ESPN Brasil & $\begin{array}{c}\text { Site, } \\
\text { Facebook, } \\
\text { Instagram, } \\
\text { Twitter, } \\
\text { YouTube, } \\
\text { LinkedIN, } \\
\text { Twitch }\end{array}$ \\
\hline Change Cast & \#T1. Ep.16 & 2020 & $\begin{array}{c}\text { Sem } \\
\text { periodicidade }\end{array}$ & $\begin{array}{l}\text { Eduardo } \\
\text { Camara }\end{array}$ & IBM & $\begin{array}{c}\text { Facebook, } \\
\text { Twitter, } \\
\text { LinkedIN }\end{array}$ \\
\hline $\begin{array}{c}\text { CWG } \\
\text { Convida LG }\end{array}$ & $\begin{array}{l}\text { Investindo em } \\
\text { e-sports }\end{array}$ & 2020 & Não informada & $\begin{array}{c}\text { Jonhyzul } \\
\text { (Streamer) e } \\
\text { LKZ (CEO da } \\
\text { CWG) }\end{array}$ & CWG & $\begin{array}{c}\text { Facebook, } \\
\text { Instagram, } \\
\text { Twitter, } \\
\text { YouTube }\end{array}$ \\
\hline $\begin{array}{c}\text { Donos da } \\
\text { Bola }\end{array}$ & - & 2019 & Não informada & $\begin{array}{c}\text { Gates, Trick, } \\
\text { Fapo, Galo }\end{array}$ & - & Twitter \\
\hline
\end{tabular}


LEMOS, FERREIRA, 2021

\begin{tabular}{|c|c|c|c|c|c|c|}
\hline Early Game & $\# 24$ & 2020 & Quinta-feira & $\begin{array}{c}\text { Alessandro } \\
\text { Jodar, Roque } \\
\text { Marques, } \\
\text { Rodrigo Faber } \\
\text { e Chandy } \\
\text { Teixeira }\end{array}$ & $\begin{array}{l}\text { Globo } \\
\text { Esporte }\end{array}$ & Site \\
\hline Empolcast & $\begin{array}{c}\text { Retrospectiva } \\
\text { Empoliga }\end{array}$ & 2020 & Não informada & $\begin{array}{c}\text { Tiago "Maker" } \\
\text { Vasconcelos }\end{array}$ & - & Twitter \\
\hline Esports 3.0 & $\begin{array}{c}\text { A } \\
\text { regulamentaç } \\
\text { ão dos } \\
\text { esportes } \\
\text { eletrônicos no } \\
\text { Brasil }\end{array}$ & 2020 & Não informada & $\begin{array}{c}\text { Leo De Biase e } \\
\text { Luiz Gustavo } \\
\text { Pacete }\end{array}$ & - & - \\
\hline $\begin{array}{c}\text { Final Level } \\
\text { Cast }\end{array}$ & \#39 & 2020 & Quarta-feira & $\begin{array}{c}\text { Dan Schettinni } \\
\text { e Rodrigo } \\
\text { Coelho }\end{array}$ & - & $\begin{array}{l}\text { Twitter, } \\
\text { Facebook, } \\
\text { Instagram, } \\
\text { YouTube }\end{array}$ \\
\hline Game Mode & $\# 2$ & 2020 & Não informada & Não informada & - & $\begin{array}{l}\text { Instagram, } \\
\text { Twitter }\end{array}$ \\
\hline BurnCast & $\begin{array}{c}\text { Giro da } \\
\text { Semana \#25 }\end{array}$ & 2020 & Não informada & $\begin{array}{c}\text { Guilherme } \\
\text { Cepeda }\end{array}$ & $\begin{array}{c}\text { Burn } \\
\text { Company }\end{array}$ & $\begin{array}{l}\text { Facebook, } \\
\text { Instagram }\end{array}$ \\
\hline $\begin{array}{l}\text { Guerrilha } \\
\text { Podcast }\end{array}$ & $\# 1$ & 2020 & Não informada & João e Cris & $\begin{array}{l}\text { Canal no } \\
\text { Twitch }\end{array}$ & Twich \\
\hline Mais eSports & $\begin{array}{l}\text { Momento } \\
\text { LPL Ep } 4\end{array}$ & 2020 & $\begin{array}{l}\text { Segunda a } \\
\text { sexta-feira }\end{array}$ & Eric Teixeira & Mais eSports & $\begin{array}{c}\text { Site, } \\
\text { Facebook, } \\
\text { Instagram, } \\
\text { Twitter, } \\
\text { YouTube, } \\
\text { Twitch }\end{array}$ \\
\hline $\begin{array}{c}\text { Mais eSports } \\
\text { Negócios }\end{array}$ & $\begin{array}{l}\text { Como } \\
\text { trabalhar no } \\
\text { mercado de } \\
\text { esports? \#12 }\end{array}$ & 2019 & Não informada & Lucas e Eric & Mais eSports & $\begin{array}{c}\text { Site, } \\
\text { Facebook, } \\
\text { Instagram, } \\
\text { Twitter, } \\
\text { YouTube }\end{array}$ \\
\hline Marketin.gg & $\begin{array}{c}\text { Panorama } \\
\text { Global para } \\
\text { Games e } \\
\text { Esports }\end{array}$ & 2020 & $\begin{array}{c}\text { Terça ou } \\
\text { Quarta-feira }\end{array}$ & $\begin{array}{c}\text { Cláudio Lima e } \\
\text { Bernardo } \\
\text { Mendes }\end{array}$ & - & Site, Twitter \\
\hline NerdCast & NerdCast 725 & 2006 & Sexta-feira & $\begin{array}{c}\text { Alexandre } \\
\text { Ottoni e Deive } \\
\text { Pazos }\end{array}$ & Jovem Nerd & $\begin{array}{c}\text { Site, } \\
\text { Facebook, } \\
\text { Instagram, } \\
\text { Twitter }\end{array}$ \\
\hline
\end{tabular}




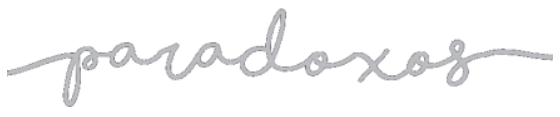

Esportes eletrônicos na pauta

da mídia sonora:

levantamento de podcasts na

plataforma de streaming Spotify

LEMOS, FERREIRA, 2021

\begin{tabular}{|c|c|c|c|c|c|c|}
\hline On Cast & - & 2020 & Não informada & $\begin{array}{c}\text { Camila Couto e } \\
\text { Weslei Silva }\end{array}$ & $\begin{array}{c}\text { Valkirias Go } \\
\text { Game }\end{array}$ & $\begin{array}{c}\text { Instagram, } \\
\text { Twitter }\end{array}$ \\
\hline Overtalk & $\# 3$ & & $\begin{array}{c}\text { Sem } \\
\text { Periodicidade }\end{array}$ & Não informada & $\begin{array}{c}\text { Liga } \\
\text { Overtake }\end{array}$ & $\begin{array}{c}\text { Instagram, } \\
\text { YouTube }\end{array}$ \\
\hline Passa a Call & Psk1 & 2020 & Não informada & $\begin{array}{c}\text { Paulo "Psik1" } \\
\text { Augusto }\end{array}$ & - & $\begin{array}{l}\text { Twitter, } \\
\text { YouTube }\end{array}$ \\
\hline Pausa Tática & $\# 10$ & 2019 & Não informada & Diogo Oliveira & $\begin{array}{c}\text { eSportsBR.c } \\
\text { om }\end{array}$ & YouTube \\
\hline $\begin{array}{l}\text { Ping - The } \\
\text { Enemy }\end{array}$ & $\begin{array}{l}\text { Especial de } \\
\text { esports }\end{array}$ & 2020 & $\begin{array}{l}\text { Segunda a } \\
\text { sexta-feira }\end{array}$ & Não informada & Omelete & $\begin{array}{c}\text { Site, } \\
\text { Facebook, } \\
\text { Instagram, } \\
\text { Twitter, } \\
\text { YouTube }\end{array}$ \\
\hline Player 1 & $\begin{array}{l}\text { Mulheres nos } \\
\text { games online }\end{array}$ & 2020 & Não informada & Não informada & - & $\begin{array}{c}\text { Site, } \\
\text { Facebook, } \\
\text { Instagram, } \\
\text { Twitter, } \\
\text { YouTube, } \\
\text { Twitch }\end{array}$ \\
\hline Podcaster & Podcaster 75 & 2018 & Quinta-feira & Tácio Schaeppi & $\begin{array}{l}\text { Associado } \\
\text { ao próprio } \\
\text { apresentador }\end{array}$ & Twitter \\
\hline PodSix & Podsix \#25 & 2020 & Não informada & Não informada & - & $\begin{array}{c}\text { Facebook, } \\
\text { Instagram, } \\
\text { Twitter }\end{array}$ \\
\hline Pouco de & & & & Douglas & & \\
\hline $\begin{array}{l}\text { Tudo, muito } \\
\text { de nada }\end{array}$ & PTMN \#4 & 2020 & Não informada & $\begin{array}{c}\text { Cândido e } \\
\text { Samuel Antila }\end{array}$ & - & Instagram \\
\hline $\begin{array}{c}\text { Rádio } \\
\text { Yuracan }\end{array}$ & - & 2020 & Não informado & Paulo Franco & $\begin{array}{c}\text { Rádio } \\
\text { Yarucan }\end{array}$ & $\begin{array}{c}\text { Facebook, } \\
\text { Instagram, } \\
\text { Twitter, } \\
\text { YouTube }\end{array}$ \\
\hline RakdosCast & Episódio 247 & 2015 & $\begin{array}{c}\text { Quarta ou } \\
\text { Quinta-feira }\end{array}$ & $\begin{array}{c}\text { Mp, Grilo e } \\
\text { Teobaldo }\end{array}$ & - & $\begin{array}{c}\text { Site, } \\
\text { Facebook, } \\
\text { Instagram, } \\
\text { Twitter }\end{array}$ \\
\hline
\end{tabular}




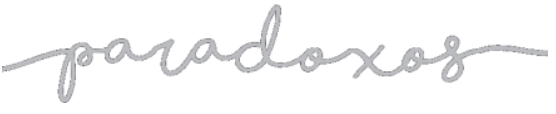

Esportes eletrônicos na pauta

da mídia sonora:

levantamento de podcasts na

plataforma de streaming Spotify

LEMOS, FERREIRA, 2021

\begin{tabular}{|c|c|c|c|c|c|c|}
\hline $\begin{array}{l}\text { Sakuras } \\
\text { Senshi }\end{array}$ & $\# 1$ & 2020 & Não informada & $\begin{array}{c}\text { Bianca "Urie", } \\
\text { Lana "Juno" e } \\
\text { Carlota }\end{array}$ & $\begin{array}{l}\text { Sakura } \\
\text { Esports }\end{array}$ & Twitter \\
\hline Sem Meme & $\begin{array}{c}\text { Franquias e } \\
\text { Semana } 1 \\
\text { CBLOL } 2020\end{array}$ & 2020 & Não informada & $\begin{array}{c}\text { Vinícius } \\
\text { "Empolgou"; } \\
\text { Nataka } \\
\text { "natakasz"; } \\
\text { Guilherme } \\
\text { 'NightFury" }\end{array}$ & $\begin{array}{l}\text { Empolgou } \\
\text { CBLoL }\end{array}$ & $\begin{array}{c}\text { Facebook, } \\
\text { Twitter }\end{array}$ \\
\hline THE CAST & $\begin{array}{l}\text { Fala muito - } \\
\text { Gestão em } \\
\text { eSports }\end{array}$ & 2018 & Não informada & $\begin{array}{l}\text { Henrique } \\
\text { Woods }\end{array}$ & THE 360 & $\begin{array}{c}\text { Site, } \\
\text { Facebook, } \\
\text { Instagram, } \\
\text { LinkedIN }\end{array}$ \\
\hline $\begin{array}{c}\text { The mitycast's } \\
\text { Podcast }\end{array}$ & $\begin{array}{l}\text { Teamfight } \\
\text { Tactics }\end{array}$ & 2019 & Não informada & Não informada & - & - \\
\hline $\begin{array}{l}\text { Tropas } \\
\text { Liberadas }\end{array}$ & \#50 & 2019 & $\begin{array}{c}\text { Pontual } \\
\text { (Durante o } \\
\text { campeonato de } \\
\text { League of } \\
\text { Legends) }\end{array}$ & Melão & $\begin{array}{c}\text { LoL Esports } \\
\text { BR }\end{array}$ & $\begin{array}{c}\text { Facebook, } \\
\text { Instagram, } \\
\text { Twitter, } \\
\text { YouTube }\end{array}$ \\
\hline TryhardCast & $\begin{array}{c}\text { Mulheres no } \\
\text { Cenário } \\
\text { Gamer! }\end{array}$ & 2019 & Não informada & $\begin{array}{c}\text { Manager, Igor, } \\
\text { Toshi e } \\
\text { Gavetinha }\end{array}$ & - & $\begin{array}{c}\text { Facebook, } \\
\text { Instagram, } \\
\text { Twitter }\end{array}$ \\
\hline $\begin{array}{l}\text { Vivendo de } \\
\text { Esports }\end{array}$ & $\begin{array}{c}\text { O marketeiro } \\
\text { de Gamers } \\
\text { Club }\end{array}$ & 2020 & Não informada & Julio Caldeira & - & $\begin{array}{c}\text { Instagram, } \\
\text { Twitter, } \\
\text { YouTube }\end{array}$ \\
\hline
\end{tabular}

Fonte: elaboração própria, 2021.

A partir da análise do Quadro 1, é possível afirmar que os podcasts voltados para a temática são relativamente novos: $62,8 \%$ foram criados em 2020 e outros 36,2\%, entre os anos de 2017 e 2019. Isso demonstra que a cobertura dos esportes eletrônicos tem potencial de demanda, além de evidenciar a sua expansão e valorização ocorridas a partir do ano de 2017. Importante registrar que os dois programas mais antigos são o NerdCast e o RakdosCast, datados de 2006 e 2015, respectivamente.

A maior parte dos programas não possui dados precisos acerca da periodicidade: $66 \%$ deles não divulgaram essa informação no texto de apresentação. Apenas $25 \%$ dos episódios possuem lançamentos periódicos registrados. Houve ainda a identificação de um programa com episódios pontuais - Tropas Liberadas -, com veiculação de inéditos somente durante o campeonato de League of Legends. 


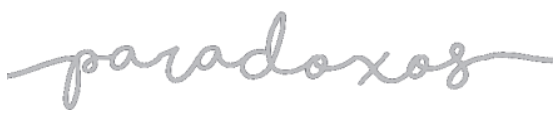

Esportes eletrônicos na pauta

da mídia sonora:

levantamento de podcasts na

plataforma de streaming Spotify

LEMOS, FERREIRA, 2021

Com relação à estrutura da equipe, somente quatro dos 35 mapeados são produzidos por uma equipe formada por mais de três pessoas, indicando a possibilidade de acúmulo de funções. Em seis dos programas, não há qualquer identificação sobre o responsável pela produção e roteirização dos episódios. Outra marca desse cenário é a falta de jornalistas setoristas face à predominância dos editores de blogs. Ainda que esses exerçam funções diferentes quando comparados aos jornalistas, o profissional do entretenimento mostra-se como uma peça importante na engrenagem da cobertura midiática, sobretudo devido ao alto nível de interesse do público pela temática e à participação nas ações de divulgação promovidas pelos campeonatos (ligas), equipes e atletas.

Por outro lado, podcasts associados a grandes veículos de comunicação evidenciam seus objetivos, formato, equipe responsável e os temas abordados. Ou seja, uma demonstração de profissionalismo frente a seus concorrentes. Globo Esporte, Sport TV, ESPN, Tech Tudo e Jovem Nerd são alguns exemplos de parcerias. Ainda que cada um deles se enquadre em uma editoria específica, que dita a forma com que é feita a cobertura, a inclusão da temática é mais um aspecto da aproximação entre jornalismo, mídias alternativas e entretenimento para atrair novos públicos (CAMPOS; FRANGE, 2016).

Vale comentar que 25 dos 35 podcasts são divulgados nas redes sociais ou produzem conteúdo exclusivo para esses espaços. Isso reforça a predominância dos meios alternativos na cobertura (IOSCOTE, 2018; KURTZ; TORREALBA, 2018). As incidências são para perfis ativos no Twitter, YouTube, Twitch, Instagram, Facebook, LinkedIn e no site próprio. Em um cenário de popularização dos eSports, as plataformas de interação já consolidadas mostram-se como opções para aumentar o alcance e a visibilidade dos programas bem como popularizar e oferecer legitimidade ao universo estudado.

$\mathrm{Na}$ fase seguinte do levantamento, foram feitas escutas ${ }^{3}$ de um episódio de cada um dos 35 podcasts mapeados. O procedimento foi feito com o objetivo de traçar

\footnotetext{
${ }^{3}$ No caso dos programas que se autodeclaram especializados na cobertura dos esportes eletrônicos (integral), optou-se por ouvir a última edição então divulgada à época do levantamento; para aqueles com pautas mais plurais (parcial), optou-se por ouvir uma edição específica com o tema dos esportes eletrônicos. No Quadro 1, conforme exposto, há o registro de qual episódio foi analisado na fase de identificação das características narrativas dos podcasts. Das 35 edições ouvidas e estudadas, três delas não estão mais
} 


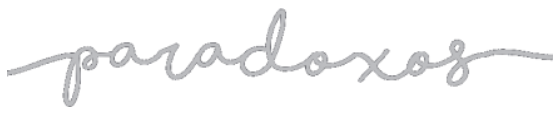

Esportes eletrônicos na pauta

da mídia sonora:

levantamento de podcasts na

plataforma de streaming Spotify

LEMOS, FERREIRA, 2021

elementos sobre dois principais aspectos: a editoria, categorizada neste estudo como 'cultura', 'esporte', 'tecnologia, mídia e games' ou 'negócios e marketing'; e o enfoque, entendido como sendo de informação e/ou entretenimento (SANTOS et al., 2015).

\section{Editorias}

O levantamento aponta que 13 programas se alinham a tecnologia, mídia e games; oito programas às de cultura; seis não têm definição clara; cinco relacionam-se à editoria de negócios e marketing; e três estão diretamente alinhadas à de esportes. A classificação foi feita a partir da leitura dos descritivos de cada podcast disponível na plataforma Spotify e da escuta de uma edição, conforme dito.

Para podcasts enquadrados na editoria 'cultura', é possível visualizar o conceito de homo ludus proposto por Huizinga (1980), no qual considera o universo dos jogos como parte fundamental da formação identitária e cultural da sociedade. Além disso, considerou-se a noção de cultura nerd e geek como parte da cultura gamer (ARCURI, 2017). Nessa abordagem, os termos dialogam, debatem e expõem novas formas de se comunicar, relacionar e produzir conteúdo focados nas tribos urbanas e nas suas peculiaridades. No podcast Sakura Senshi, por exemplo, enquadrado como cultura, as apresentadoras Bianca Lano e Carlota discutem sobre séries, design gráfico, filmes, games no geral e o papel das mulheres no cenário de eSports.

Para a editoria 'esportes', foram identificados os programas que se apropriaram das estruturas narrativas e jargões dos esportes tradicionais para melhor tradução de seu conteúdo. Para mais, foram evidenciados os programas que trouxeram maior relevância sobre temáticas envolvendo a vida dos atletas e pautas esportivas pertinentes para a Sociedade do Espetáculo (LIMA; MOTA, 2019). O podcast Around The Rift, associado ao portal Mais e-Sports, é um exemplo disso. Embora seu principal objetivo seja compartilhar notícias e novidades dos esportes eletrônicos, os responsáveis pela cobertura tratam os campeonatos da mesma forma

disponíveis na plataforma o que comprometeu a sua correta identificação no quadro, tendo em vista que esta ação de registro foi posterior ao processo de escuta dos episódios selecionados.

DOI: http://doi.org/10.14393/par-v6n1-2021-60844 - Paradoxos, Uberlândia, v. 6, n. 1, p. 86-102, jan./jun. 2021| 97 


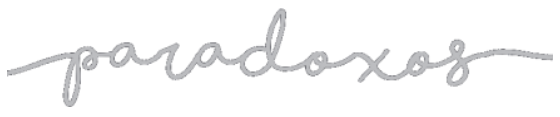

Esportes eletrônicos na pauta

da mídia sonora:

levantamento de podcasts na

plataforma de streaming Spotify

LEMOS, FERREIRA, 2021

que os torneios de esportes tradicionais, explorando linguagens e os elementos narrativos do jornalismo esportivo.

Já a editoria 'tecnologia, mídia e games' trata, especificamente, sobre o universo digital e dos jogos, explorando questões técnicas, novidades, atualizações nos games, entre outras. Pig - The Enemy, podcast produzido pelo Omelete, enquadra-se nesta categoria. Seguindo a mesma linha editorial do veículo ao qual está associado, o objetivo é integrar os esportes eletrônicos como parte do setor da tecnologia, cabendo sua análise e seu tratamento serem enquadrados em inovação tecnológica.

A editoria 'negócios e marketing' diz respeito aos programas que abordam esportes eletrônicos numa perspectiva mercadológica. Portanto, seu conteúdo é voltado para a formação e capacitação profissional nos mais variados setores que compõem o campo, além dos dados financeiros do setor, como a expansão e o faturamento das marcas e temas correlatos. Em Vivendo de Esports, por exemplo, Julio Caldeira realiza entrevistas com profissionais dos eSports para demonstrar um pouco mais do mercado para compreender como é, e de que forma se dá o trabalho dessas pessoas.

\section{Enfoque}

O levantamento também contempla os enfoques da informação e do entretenimento e a possível relação entre eles. Nesta etapa, identificou-se a forma com que o conteúdo é apresentado nos programas ouvidos. Foram mapeadas três modalidades: 'entretenimento/diversão' (17); 'informação' (16); 'informação, entretenimento/diversão' (2). Considerou-se como 'informação' os podcasts que visam informar o ouvinte a respeito de pautas de interesse público, adotando uma estrutura semelhante à dos noticiários de rádio. Já 'entretenimento/diversão' representa programas que criam conteúdos próprios e tratam os eSports enquanto diversão e lazer, resultando em um formato mais informal e menos jornalístico. Já a categoria 'informação, entretenimento/diversão' é um mix dos dois formatos e oscila entre a notícia e o entretenimento.

Por ser produzido de forma direcionada, os podcasts tratam temáticas específicas, a partir de conteúdos exclusivos e relevantes para os seus consumidores (CHAGAS, 2020). Diferentemente dos programas de rádio, no qual o interesse público e o valor DOI: http://doi.org/10.14393/par-v6n1-2021-60844 - Paradoxos, Uberlândia, v. 6, n. 1, p. 86-102, jan./jun. 2021| 98 


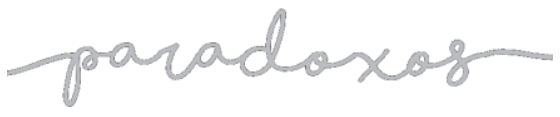

Esportes eletrônicos na pauta

da mídia sonora:

levantamento de podcasts na

plataforma de streaming Spotify

LEMOS, FERREIRA, 2021

notícia são prioridades, na mídia sonora, cada detalhe é planejado de modo a cumprir com uma solicitação, uma encomenda do seu consumidor.

Além disso, o infotenimento faz-se presente por meio da apropriação de elementos e técnicas do jornalismo para construção de sua abordagem e apresentação do seu conteúdo. $\mathrm{O}$ uso de entrevistas associado à técnica de debates remete às tradicionais mesas-redondas, frequentemente presentes nos programas de rádio e de TV. Outro exemplo, é a transmissão de notícias em forma de boletins e retrospectivas da semana, apontando os resultados dos campeonatos e ou acontecimentos marcantes para o setor.

Mesmo nos programas com enfoque mais voltado ao entretenimento, nos quais a diversão e o lazer sobrassem a função informativa, as entrevistas e notícias, muito utilizadas no jornalismo, têm seu valor. Nesses casos, fica evidente a importância desse formato na construção de uma narrativa profissional. Mesmo na diversão, diferentes pontos de vista são necessários para trazer credibilidade, já que apresentam mais de uma interpretação para um mesmo fato. Já as notícias mostramse como fundamentais para embasar as discussões e expor acontecimentos de interesse do público.

Em programas com cunho informativo, acontece o mesmo fenômeno: a união e integração entre unidades noticiosas, de diferentes formatos, com o propósito de construir um produto mais interessante e pertinente para o público-alvo. $\mathrm{O}$ jornalismo tradicional sustenta-se na neutralidade, enquanto o atual jornalismo, resultante da emergência de novas mídias (podcast) e temáticas contemporâneas (eSports), o objetivo é informar, à medida que diverte. Neste cenário, as redes sociais mostram-se como opção prioritária para a divulgação desses materiais, visto que permitem maior aproximação e diálogo com o público.

\section{Considerações finais}

A análise dos dados do mapeamento realizado permite dizer que: (a) a cobertura dos eSports é plural, cabendo nuances do entretenimento e da informação na sua abordagem; (b) o segmento ainda está em formação, por isso, adota e se apropria de elementos de diferentes editorias do jornalismo para a construção de sua narrativa; (c) 


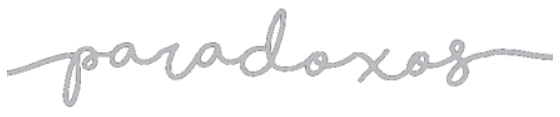

Esportes eletrônicos na pauta

da mídia sonora:

levantamento de podcasts na

plataforma de streaming Spotify

LEMOS, FERREIRA, 2021

faz-se necessário a aplicação de técnicas jornalísticas para melhor profissionalizar o segmento; e (d) estudar os eSports exige um esforço para compreender um contexto cultural, social e econômico de produção de conteúdo.

Um dos principais pontos perceptíveis é a pluralidade entre editoriais: tecnologia, mídia e games; negócios e marketing; cultura e esportes. A abrangência e a variedade de enfoques podem ser um ponto positivo quando norteiam e guiam a cobertura midiática de um segmento novo, criando parâmetros de análise e compreensão. No entanto, pode ser um ponto negativo ao dificultar a categorização e a identificação das características do próprio segmento, visto que os esportes eletrônicos se tornam um híbrido à medida que não é nada em específico. Ao analisar a situação a partir do macro, do levantamento, depara-se com uma relação complexa, a pluralidade é uma característica do tipo de cobertura, ou seja, é o resultado dos outros fatores. Mas é, também, causadora de tudo isso, da falta de profissionalismo, da relação sensível entre editores de blogs e jornalistas.

O levantamento aponta tratar-se de um campo de atuação profissional e cobertura midiática em autodescoberta e projeção. A cobertura midiática dos esportes eletrônicos busca por uma identidade alinhada mais à cobertura jornalística, especialmente, com uma abordagem mais do viés esportivo e econômico do segmento. Além disso, entende-se que é uma cobertura marcada pela subjetividade, visto que não possui limites definidos, a paixão e a emoção sobressaem, muitas vezes, ao valor notícia. Como resultado, transforma-se em um ponto de encontro para profissionais de diferentes setores, produzindo um produto que não se enquadra nas características do jornalismo nem dos criadores de conteúdo. Por último, é restrita quando, ao mesmo tempo em que é plural, é exclusiva em alguns aspectos referentes ao seu formato, gerando ambiguidades.

A relação dos pontos abordados no levantamento indica temáticas que podem tornar-se objetos de estudos futuros. Além da continuidade, atualização e ampliação do levantamento proposto, novas pesquisas podem se orientar pelo pluralismo de vozes e temáticas na cobertura midiática dos esportes eletrônicos; o (não)profissionalismo; o papel das desenvolvedoras de games e sua relação com a 
imprensa; a importância da experiência do jornalista para a cobertura imparcial e objetiva, dentre outras temáticas.

\section{Referências}

ARCURI, Mariana Conde Moraes. Quadrinhos e febre geek: relato de uma ida à comic com experience. Revista Escrita, n. 22, 2017. DOI:

https://doi.org/10.17771/pucrio.escrita.28871.

BERNARDO, Kaluan Boranini. E-Sports: um estudo de caso sobre como a relação entre esporte e videogame se dá na sociedade capitalista contemporânea. 2016.

Dissertação (Mestrado em Comunicação) - Faculdade Cásper Líbero, São Paulo, 2016.

CAMPOS, Anderson Gurgel; FRANGE, Marcelo Bechara. Jornalismo no mundo dos esports: reflexões sobre os desafios para a cobertura dos esportes eletrônicos na prática jornalística. Revista Comunicare. São Paulo, 2017.

CCXP. Para nós o mundo é assim. [s. 1.], [s. d.]. Disponível: https://www.ccxp.com.br/a-ccxp. Acesso em: 26 fev. de 2021.

CHAGAS, Luãn. Podcast consolida-se como formato diverso e de grande alcance no Brasil. [Entrevista concedida a Safira Campos]. Pnb online, [s.1], 03 mai. 2020. Disponível em: https://www.pnbonline.com.br/geral/podcast-consolida-se-comoformato-diverso-e-de-grande-alcance-no-brasil/65732. Acesso em: 26 fev. 2021.

CONFEDERAÇÃO BRASILEIRA DE ESPORTS. O que são eSports? [s. 1.], [s. d.]. Disponível em: http://cbesports.com.br/esports/esports-o-que-sao/. Acesso em: 03 maio 2021.

CRESWELL, John W. Projeto de pesquisa: métodos qualitativo, quantitativo e misto. Porto Alegre: Artmed, 2007.

DALLEGRAVE, Letícia. E-Sports como entretenimento: análise de conteúdo do Campeonato Brasileiro de League of Legends. In: $41^{\circ}$ Congresso Brasileiro de Ciências da Comunicação, 2018, Joinville. Anais[...]. Intercom, 2018.

FERREIRA, Kellison. Saiba como ouvir podcasts usando os 7 melhores agregadores disponíveis. RockContent, [s.1.], 29 jan. 2020. Disponível em:

https://rockcontent.com/br/blog/como-ouvir-podcast/. Acesso em: 03 maio 2021.

FREITAS, Beatriz; MENDONÇA, Raphael Leal; MUSTARO, Pollyana N. Análise de Podcasts Brasileiros sobre Jogos Eletrônicos. Trilha de Games \& Cultura, 2010. Florianópolis: IX SB Games, 1010. 


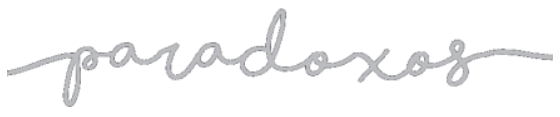

Esportes eletrônicos na pauta

da mídia sonora:

levantamento de podcasts na

plataforma de streaming Spotify

LEMOS, FERREIRA, 2021

HAGUI, Lucas. Space Invaders e Spacewar: os primeiros campeonatos de eSports do mundo.

Versus, [s.1.], 13 set. 2018. Disponível em: https://vs.com.br/artigo/space-invaders-e spacewar-os-primeiros-campeonatos-de-esports-do mundo. Acesso em: 03 maio 2021.

HUIZINGA, J. Homo Ludens. São Paulo: Ed. Perspectiva, 1980.

IOSCOTE, Fabia. Mídia e e-Sports: o contexto midiático e a representação dos jogadores de esportes eletrônicos. In: XVII SBGames, 2018, Foz do Iguaçu. Foz do Iguaçu: SBGames 2018, 2018.

JENKINS, Henry. Cultura da Convergência. São Paulo: Aleph, 2013.

KURTZ, Adriana Schryver; TORREALBA, Alex Bruno Dudschig. Os e-sports com uma nova alternativa para o jornalismo esportivo. In: XIX Congresso de Ciências da Comunicação na Região Sul, 2018, Cascavel. Anais [...] Cascavel: Intercom, 2018.

LIMA, Luísa Guimarães; MOTA, Guilherme. Jornalismo Esportivo no âmbito dos Esports: uma análise da cobertura jornalística da sua possível inserção nos jogos olímpicos. In: XXI Congresso de Ciências da Comunicação na Região Centro-Oeste, 2019, Goiânia. Anais [...] Goiânia: Intercom, 2019.

NEWZOO. Newzoo Global Esports Market Report. Newzoo, [s. 1.], [s. d.]. Disponível em: https://newzoo.com/insights/trend-reports/newzoo-global-esports-market-report2020-light-version/. Acesso em: 26 fev. 2021.

REIS, Igor Silva. Análise dos fatores que influenciam o consumo e intenção de uso da plataforma de streaming Twitch TV no Brasil. 2018. Trabalho de Conclusão de Curso (Graduação em Administração) - Universidade Federal de Uberlândia, Uberlândia, 2018.

SANTOS, Heloísa Souza. et al. Infotenimento: Os Novos Rumos Do Jornalismo Na Cultura Da Convergência. In: XX Congresso de Ciência da Comunicação na Região Sudeste, 2015, Uberlândia. Anais [...] Uberlândia: Intercom, 2015.

SOUZA, Doralice Lange de; SANTOS, Silvan Menezes dos; MEZZAROBA, Cristiano. Jornalismo Esportivo e Infoentretenimento: a (possível) sobreposição do infoentretenimento à informação no conteúdo jornalístico dos esportes. Revista Corpoconsciência, Cuiabá, v. 21, nº 2, maio/ago., 2017. 